\title{
Self reported rhinitis is a significant problem for patients with asthma
}

\author{
Samantha Walker*, Aziz Sheikh
}

Director of Research, National Respiratory Training Centre, The Athenaeum, 10 Church Street, Warwick, CV34 4AB UK

Received 8 October 2004; accepted 31 October 2004

\section{Summary}

Background: There is increasing interest in the possibility that rhinitis ard distrina are intricately interlinked. The aim of this baseline audir/as to investigate the prevalence and characteristics of rhinitis symfiteins in a large-scale IK iniliaic care-based survey of patients vith astinna.

Methods: A questionnaire and the presence/absence and type or nasal symptoms, seasonal variations, and trigger factor $\sqrt{ }$ a) covtoped and piloted. This was then distributed among approximately 10,500 patients with clinician-diagnosed asthma via a national database of practice nurses.

Results: We achieved a response from 7,129 patients $(68 \%)$. Of these, $76 \%(n=5,420)$ had symptoms indicative of rhinitis as shown by the presence of more than one of the following: nasal blockage; runny nose; sneezing; and itchy eyes, ears or palate. $58 \%$ reported predominantly seasonal symptoms and $42 \%$ predominantly perennial symptoms. Sneezing was reported in a significantly greater proportion of patients with seasonal (66\%) than perennial (58\%) symptoms, together with itchy eyes/ears/palate (seasonal 60\%, perennial 48\%) and rhinorrhoea (56\%, 51\%) (all $p \leq 0.001)$. Symptoms of nasal blockage were more commonly reported in the group with perennial symptoms (perennial $61 \%$, seasonal $53 \%)(p<0.001)$.

Conclusions: In this large national baseline survey, $76 \%$ of patients with asthma reported symptoms indicative of rhinitis. In view of the very high prevalence of rhinitis among people with asthma, we suggest that the diagnosis of rhinitis is considered in all those with asthma.

(c) 2004 General Practice Airways Group. Published by Elsevier Ltd. All rights reserved.

\section{Introduction}

* Corresponding author. Tel.: +44 1926838975 ; fax: +44 1926493224 .

E-mail address: s.walker@nrtc.org.uk (S. Walker).
Allergic rhinitis is one of the commonest chronic problems presenting in primary care. The prevalence of seasonal (intermittent) allergic rhinitis, 
or hayfever, along with many other allergic conditions, has increased steadily over the past $40-50$ years, such that around $15 \%$ of adults and $20 \%$ of children currently suffer from seasonal rhinitis, conjunctivitis or asthma symptoms [1]. Rhinitis symptoms have been shown to cause significant morbidity, causing impaired concentration [2], poor productivity and decreased learning ability in children and adolescents [3].

There is an increasing body of evidence which supports a link between asthma and rhinitis. Rhinitis is a risk factor for the development of asthma [4], and among the possible trigger factors for rhinitis and asthma some allergens such as cat dander and house dust mite are well known to affect the nose and the lungs [5]. Many patients with allergic rhinitis have increased non-specific bronchial sensitivity $[6,7]$ during seasonal [8] and perennial [9] allergen exposure. Asthma is more common [10] and bronchial hyperresponsiveness more common and more severe in perennial compared to seasonal rhinitis $[9,11]$. Patients with seasonal allergic rhinitis develop seasonal increases in nonspecific bronchial responsiveness but not necessarily asthma symptoms, and these patients often have normal bronchial responsiveness during the winter months [12]. Bronchial responsiveness is also in creased in viral rhinitis $[13,14]$, and following nasal allergen challenge $[15,16]$. The se arservations sug. gest that b onchal inflan ination is assoside with nasal inflanmation, an idea $\sqrt{2}\left(\frac{1}{4}\right)$ is supported by the fact that bronchial hyperreactivity is reversed by intranasal treatment with sodium cromoglycate [17], nedocromil sodium [18] and corticosteroids $[19,20]$.

Patients with co-existent asthma and rhinitis who are receiving treatment for allergic rhinitis have a significantly lower risk of attending accident and emergency departments and hospitalizations for asthma [21]. To investigate the extent of the problem in the UK, this study aimed to discover the prevalence of rhinitis among patients with a clinician-diagnosis of asthma in UK primary care.

\section{Methods}

\section{Study design}

239 UK general practices were recruited via a national (commercial) database. Patients were identified from the practice asthma registers by practice nurses and asked to complete a pre-piloted questionnaire at the time of their routine asthma review.

\section{Patients}

Eligible subjects were patients of any age with a physician- or nurse- diagnosis of asthma who agreed to complete a questionnaire. Parents completed the questionnaire on behalf of children.

\section{Questionnaire}

A short questionnaire was developed by a multidisciplinary group with expertise in rhinitis/ asthma and piloted before use. Questions enquired about the presence/absence of nasal symptoms and, if present, the type of nasal symptoms experienced, seasonal variations, trigger factors and the impact of these on asthma symptoms. Information about the types of medication used to treat rhinitis and patients' access to treatment were also collected. Questionnaires were distributed by practice nurses between May 2001 and May 2002.

\section{Statistical analysis}

Descrintive aftises were employed to summarise relute and differences in the number of patients reportir's seasticiond and perennial symptoms were con) pared using the chi-square test.

\section{Results}

\section{Clinical data}

We achieved a response rate of $68 \%(n=7,129)$. Respondents had a mean age of $33(S D \pm 20$, range $1-91) ; 56 \%(n=2,929)$ of respondents were women. Among respondents, unanswered individual questions resulted in $10-15 \%$ missing data.

\section{Rhinitis symptoms}

$76 \% \quad(n=5,381) \quad$ of respondents reported experiencing one or more of the following symptoms in the absence of a cold: blocked nose (56\%); sneezing $(63 \%)$; runny nose $(54 \%)$; and itchy eyes/ears/palate (55\%).

\section{Link between rhinitis and asthma}

Of the 5,381 patients reporting rhinitis symptoms, 49\% (2356) reported that their nasal symptoms made their asthma worse; 48\% (2312) reported these had no impact on asthma symptoms, whilst 
3\% (105) reported that their nasal symptoms improved their asthma.

\section{Seasonal vs. perennial symptoms}

The majority $(58 \%)$ of patients experienced seasonal rhinitis symptoms occurring for one or more months during the year with $42 \%$ reporting perennial symptoms. Sneezing was reported in a significantly greater number of patients with seasonal (66\%) than perennial (58\%) symptoms, together with itchy eyes/ears/palate (seasonal $60 \%$, perennial $48 \%$ ) and rhinorrhoea $(56 \%, 51 \%)$ (all $p \leq 0.001$ ). Symptoms of nasal blockage were more commonly reported in the group with perennial symptoms (perennial 61\%, seasonal 53\%) $(p<0.001)$.

With respect to asthma, $42 \%$ of respondents said that their asthma was the same all year round, 37\% said that their asthma was worse in the summer, and $21 \%$ that it was worse in the winter.

\section{Allergen triggers}

Pollens were the commonest reported trigger with $60 \%$ of patients reporting worsening symptoms on exposure to pollens. Dust (39\%) and exposure to animals (32\%) were also commonty ereprted triggers although $16 \%$ "of respondents reportec symptoms of EXOD triggers.

\section{Treatment}

The majority of patients who reported taking treatment were taking a non-sedating anti-histamine (loratidine $31 \%(n=1254)$; cetirizine $17 \% \quad(n=666) ;$ desloratidine $8 \% \quad(n=329) ;$ and fexofenadine $4 \% \quad(n=146)) . \quad 13 \% \quad(n=521)$ of respondents were taking a sedating anti-histamine (chlorpheniramine) and 6\% (235) an unspecified anti-histamine.

Beclometasone was the most commonly taken nasal spray $(25 \% ; n=1,007)$, followed by fluticasone $(12 \% ; n=487)$, mometasone $(8 \% ; n=305)$ and budesonide $(4 \% ; n=177) .5 \%(n=198)$ of patients were taking an unspecified nasal spray. $87 \%$ of respondents reported getting their treatment from their general practitioner and 16\% from their pharmacist.

\section{Discussion}

In this large community-based UK survey of over 7,000 patients with asthma, $76 \%$ reported symptoms of rhinitis in the absence of a cold. Over half $(58 \%)$ experienced seasonal symptoms, the majority reporting symptoms between May and July; $42 \%$ reported symptoms all year round. The spectrum of symptoms varied between seasonal and perennial sufferers; sneezing, rhinorrhoea and itchy eyes/ears/palate were reported more commonly in the seasonal rhinitis group, but nasal blockage was reported more commonly in the perennial rhinitis group. Rhinitis symptoms were believed to have an adverse effect on asthma by $49 \%$ of patients.

It has been observed that allergic rhinitis and asthma coexist in the same patients, and recent guidelines [22] recommend routine assessment of rhinitis in patients with asthma. Studies have shown that inhaling allergen causes nasal inflammation and that application of intranasal allergen causes bronchial inflammation [23,24]. Treatment with topical nasal corticosteroids appears to improve airways hyper-responsiveness [25]. Seasonal and perennial rhinitis have both been shown to affect health-related quality of life $[12,26,27]$ and rhinitis has been shown to have significantly greater impact on quality of tife than asthma [28]. The high pelicentage of patients with concomitant astivia and rninitis in this study merits improved recognition and eatenent of rhinitis symptoms in order fonprove quality of life.

An interesting observation was the difference in the spectrum of symptoms reported by patients with seasonal and perennial symptoms. This is in keeping with nasal allergen challenge studies which have identified different symptom profiles between intermittent (seasonal) and persistent (perennial) rhinitis, with nasal blockage being the primary symptom in persistent disease [29,30]. Rhinitis management guidelines [22] suggest that the first line treatment for moderate or persistent symptoms should be a regular topical nasal steroid although in this study anti-histamines were the most commonly used drugs. This may be because patients prefer a tablet to a nasal spray or because they feel that nasal sprays are ineffective. Anti-histamines, however, are known to be less effective than nasal steroids at treating symptoms of nasal blockage [31] and so the correct and regular application of a nasal steroid is likely to be the most effective treatment.

We found that the most commonly reported treatments for rhinitis were anti-histamines and topical nasal steroids. A significant number (13\%) of patients were taking a sedating anti-histamine, a treatment strategy which is no longer recommended [22] because of effects on the central nervous system such as somnolence, diminished alert- 
ness and slow reaction time - these effects being similar to those produced by alcohol or major tranquillizers. Sedating anti-histamines have also been shown to compound the effects of allergic rhinitis by impairing learning ability [3]. Health professionals should be aware of these effects and, because patients can experience considerable sedation without being aware of it, a non-sedating preparation should be prescribed. The number of patients in this survey who received medication from their general practitioner was high $(87 \%)$ although this is unsurprising given that patients in the study were selected via their general practitioners and so were more likely to receive prescription-only rather than over-the-counter medicines.

Despite the availability of effective drug treatments, the majority of patients in the UK report 'poor' or 'partial' symptom control [32]. There may be a number of reasons for this. Compliance with treatment is often poor, although reasons may be multifactorial; the sedative nature of the still widely-prescribed first generation anti-histamines, steroid-phobia, and the lack of information given to patients may all play a part. Symptoms are trivialised by patients and healthcare professionals alike, although it is usually possible to impro'? the morbidity associated with hayfeven by the im plementation of practical surdelii es, scarting treat ment early irotine seasen, and by ensurirlg that patients have realistic expect $\tilde{A}^{\prime}$ if. of the various treatments available.

It is likely that the primary differences between seasonal (sneezing, itching, rhinorrhea) and perennial (nasal blockage) symptoms observed in this study are the result of intermittent versus persistent allergen exposure. Pollen counts rise and fall during the pollen season, giving repeated but not necessarily constant exposure to allergen, whilst constant levels of house dust mite or cats in the home lead to prolonged exposure. Symptoms which occur immediately on exposure to allergen include sneezing, nasal and conjunctival itching, and rhinorrhea. During persistent exposure, for example to house dust mite or cat allergen in the bedroom, the primary symptom is usually nasal blockage. For effective management, it is important that both immediate (intermittent) and persistent symptoms are recognised and treated appropriately.

In summary, we have found that rhinitis is a significant problem for the majority of patients with asthma. Evaluation of rhinitis should be an integral part of an asthma consultation, and symptoms should be treated according to evidencebased guidelines.

\section{References}

[1] Strachan DP. Epidemiology of hayfever: towards a community diagnosis. Clin Exp Allergy 1995;25:296-303.

[2] Juniper EF, Guyatt GH. Development and testing of a new measure of health status for clinical trials in rhinoconjunctivitis. Clin Exp Allergy 1990;21:77-83.

[3] Vuurman EPF, van Veggel LMA, Uiterwijk MMC, Leutner D, O'Hanlon JF. Seasonal allergic rhinitis and antihistamine effects on childrens' learning. Annals of Allergy 1993;71:121-6.

[4] Wright AL, Holberg CJ, Martinez FD, Halonen M, Morgan M, Taussig LM. Epidemiology of physician-diagnosed allergic rhinitis in childhood. Pediatrics 1994;94:895-901.

[5] Sibbald B, Rink E. Epiemiology of seasonal and perennial rhinitis: clinical presentation and clinical history. Thorax 1991;46:895-901.

[6] Townley RG, Ryo UY, Kolotkin BM, Kang B. Bronchial sensitivity to methacholine in current and former asthmatic and allergic rhinitis patients and control subjects. J Allergy Clin Immunol 1975;56:429-42.

[7] Ramsdale EH, Morris MM, Roberts RS, Hargreave FE. Bronchial responsiveness to methacholine in chronic bronchitis: relationship to airflow obstruction and cold air responsiveness. Thorax 1984;39:912-8.

[8] Gerblich AA, Schwartz HJ, Chester EH. Seasonal variation of airway function in allergic rhinitis. J Allergy Clin Immunol 1986;77:676-81.

[9] Verdiani P, Di Carlo \&, B ronti A. Wifferent prevalence and desree oi nosstectic oronchial hyperreactivity beciven stasonal ano perennial rhinitis. Clin Exp Allergy 1996;26:61-7.

[10] Levn or: B, Bo Isquet J, Neukirch C, Liard R, Neukirch F. Peennal rhinitis: an independent risk factor for asthma in non-atopic subjects: results from the European Community Respiratory Health Survey. J Allergy Clin Immunol 1999:301-4.

[11] Prieto JL, Gutierrez V, Berto JM, Camps B. Sensitivity and maximal response to methacholine in perennial and seasonal allergic rhinitis. Clin Exp Allergy 1996;26:61-7.

[12] Walker SM, Pajno G, Torres Lima M, Wilson DW, Durham SR. Grass pollen immunotherapy for seasonal rhinitis and asthma: A randomised controlled trial. J Allergy Clin Immunol 2001;107:87-93.

[13] Lemanske Jr R, Dick EC, Swenson CA, Vrtis RF, Busse WW. Rhinovirus upper respiratory infection increases airway hyperreactivity and late asthmatic reactions. J Clin Invest 1989;83:1-10.

[14] Sterk PJ. Virus-induced airway hyperresponsiveness in man. Eur Resp J 1993;6:894-902.

[15] Corren J, Adinoff AD, Irvin CG. Changes in bronchial responsiveness following nasal provocation with allergen. J Allergy Clin Immunol 1992;89(2):611-8.

[16] Aubier M, Levy J, Clerici C, Neukirch C, Cabrieres F, Herman D. Protective effect of theophylline on bronchial hyperresponsiveness in patients with allergic rhinitis. Am Rev Respir Dis 1991;143(2):346-50.

[17] Lowhagen O, Rak S. Modification of bronchial hyperreactivity after treatment with sodium cromoglycate during pollen season. J Allergy Clin Immunol 1985;75:460-7.

[18] Dorward AJ, Roberts JA, Thomson NC. Effect of nedocromil sodium on histamine airway responsiveness in grass pollen sensitive asthmatics during the pollen season. Clin Allergy 1986;16:309-15.

[19] Sotomayor H, Badier M, Vervloet D, Orehek J. Seasonal increase of carbachol airway responsiveness in patients al- 
lergic to grass pollen. Reversal by corticosteroids Am Rev Respir Dis 1984;130(56):58.

[20] Prieto L, Berto JM, Gutierrez V, Tornero C. Effect of inhaled budesonide on seasonal changes in sensitivity and maximal response to methacholine in pollen-sensitive asthmatic subjects Eur Resp J 1994;130:56-8.

[21] Crystal-Peters J, Neslusan C, Crown WH, Torres A. Treating allergic rhinitis in patients with comorbid asthma: the risk of asthma-related hospitalizations and emergency department visits. J Allergy Clin Immunol 2002;109:57-62.

[22] Bousquet J, Van Cauwenberge P, Khaltaev N. Allergic Rhinitis and its Impact on Asthma. J Allergy Clin Immunol 2001;108(5):s147-333.

[23] Calhoun WJ, Jarjour NN, Gleich GJ, Stevens CA, Busse WW. Increased airway inflammation with segmental versus aerosol antigen challenge. Am Rev Respir Dis 1993;147(6, part 1):1465-71.

[24] Corren J, Adinoff AD, Irvin CG. Changes in bronchial responsiveness following nasal provocation with allergen. J Allergy Clin Immunol 1992;89(2):611-8.

[25] Corren J, Adinoff AD, Buchmeier A. Nasal beclomethasone prevents the seasonal increase in bronchial responsiveness in patients with allergic rhinitis and asthma. J Allergy Clin Immunol 1992;90:250-6.

[26] Sheikh AS, Khan-Wasti S, Fletcher M, Walker SM. Quality of life in patients with perennial rhinitis. Eur Resp J 2004;24(48):P626.
[27] Bousquet J, Duchateau J, Pignat JC, Fayol C. Improvement of quality of life by treatment with cetirizine in patients with perennial allergic rhinitis as determined by a French version of the SF-36 questionnaire. J Allergy Clin Immunol 1996;98:309-16.

[28] Leynaert B, Neukirch C, Liard R, Bousquet J, Neukirch F. Quality of life in allergic rhinitis and asthma. A populationbased study of young adults. Am J Respir Care Med 2000;162(4 pt 1):1391-6.

[29] Naclerio RM, Meier HL, Kagey-Sobotka A, Adkinson NF, Meyers DA, Norman PS. Mediator release after nasal airway challenge with allergen. Am Rev Respir Dis 1983;128:597-602.

[30] Naclerio RM, Proud D, Togias A, Adkinson NF, Meyers DA, Kagey-Sobotka A. Inflammatory mediators in late antigen-induced rhinitis. N Eng J Med 1985;313:6570.

[31] Weiner JM, Abramson MJ, Puy RM. Intranasal corticosteroids versus oral $\mathrm{H}_{1}$-receptor antagonists in allergic rhinitis: systemic review of randomised controlled trials. Brit Med J 1998;317:1624-9.

[32] White P, Smith H, Baker N, Davis W, Frew A. Symptom control in patients with hay fever in UK general practice: how well are we doing and is there a need for allergen immunotherapy? Clin Exp Allergy 1998;28:26670 .

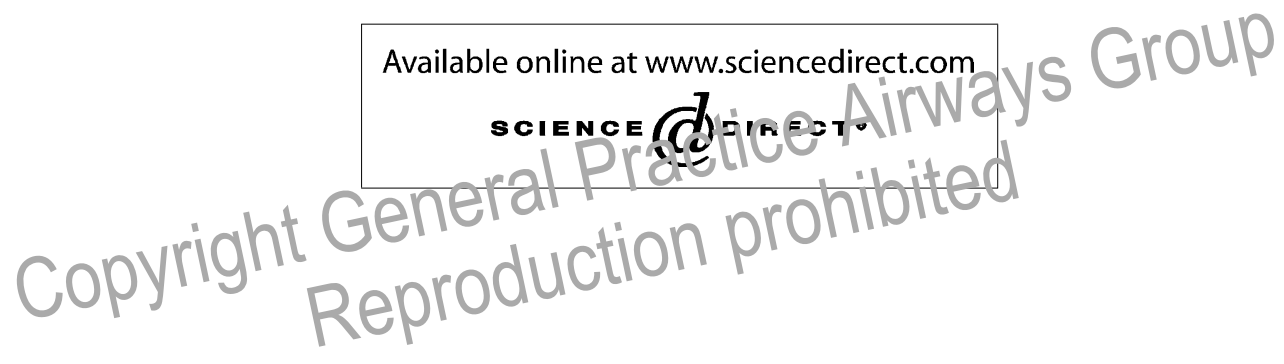

Available online at http://www.thepcrj.com 